\title{
Craniometaphyseal dysplasia
}

\author{
H. V. NEMA, J. S. MATHUR, AND T. P. SRIVASTAVA* \\ From the Department of Ophthalmology and Orthopaedics, * Institute of Medical Sciences, \\ Banaras Hindu University, Varanasi 5, India
}

Craniometaphyseal dysplasia is a rare congenital anomaly involving the modelling of the metaphyses and characterized by pronounced splaying of the metaphyseal ends of the long bones, enormous thickening of the base of the skull, and absence of pneumatization of the paranasal sinuses and mastoid region. Pyle (I93 I) reported the first case and the disease is sometimes named after him. Ellis (1934) described two early cases of Pyle's disease in siblings, and Gemmell (1935), Halliday (1949), and Mori and Holt (1956) highlighted its cranial manifestations. Rubin (1964) discussed the anomaly in great detail. The need for a complete skeletal survey in making a correct diagnosis has been emphasized on several occasions.

Cases of craniometaphyseal dysplasia have recently been seen in two brothers. As there are very few reports of Pyle's disease in siblings in the literature (Ellis, 1934; Field, 1939; Lehmann, I957; Millard, Maisels, Batstone, and Yates, 1967), these cases merited reporting.

\section{Case reports}

Case I, a boy aged 4 years, was admitted to the Bhuwalka Eye Hospital, Varanasi, in May, r969, with a history of gradual diminution of vision in both eyes over the previous 3 months. He had been born at full term, by a normal delivery, but all the developmental milestones were delayed. A deformity of the skull had developed at the age of 9 months.

The parents and grandparents of the child showed no abnormalities but his younger brother (Case 2) had a similar skull deformity.

\section{Examination}

The child had a slightly enlarged skull with prominent frontal bossing, a characteristic broad flat nose, and hypoplastic mesodontic teeth. His intelligence was normal.

The circumference of the skull was $5 \mathrm{I} \cdot 2 \mathrm{~cm}$. and the vault measured $52 \cdot 8 \mathrm{~cm}$. Both eyes had doubtful perception of light and showed coarse nystagmoid movements. There were central irregular opacities in both corneae. The pupils were semidilated and reacted very sluggishly to light. Fundus examination revealed bilateral primary optic atrophy with absence of foveal reflexes.

There were swellings over the wrist, elbow, and knee joints and marked bilateral genu valgum.

A full blood count and studies of the blood chemistry were non-contributory.

\section{Radiology}

$X$ rays of the skull showed thickening of the base with absence of pneumatization of the paranasal sinuses and mastoid region. Sclerosis was also seen in the vault and orbital ridges (Fig. I). Both optic foramina were irregularly sclerosed. 


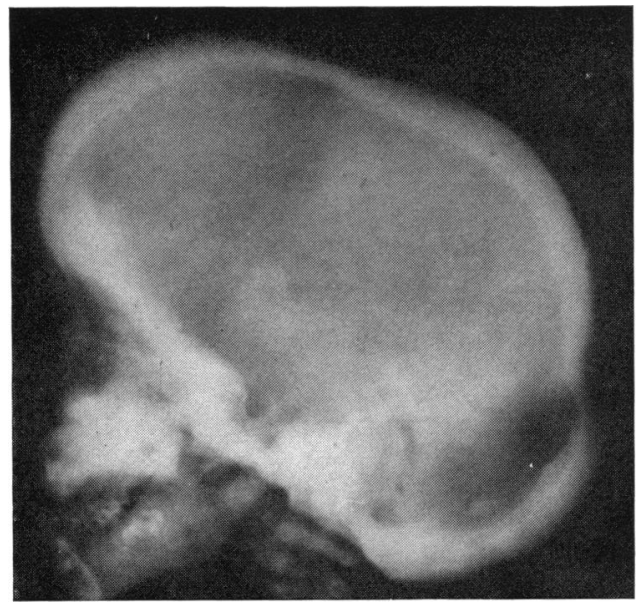

FIG. I Case I. Lateral $x$ ray of skull, showing sclerosis of the vault and absence of pneumatization of the mastoid region

The long bones showed splaying of the metaphyses, sclerosis of the shafts, and radiolucency of the lower ends of femur, both ends of the tibia, and the lower ends of the ulna and radius. The other flat bones did not show any deformity.

Case 2, the younger brother of Case 1 , aged 18 months, appeared well except for an inability to stand firmly.

The skull was relatively large with marked frontal bossing (Fig. 2). The face showed a depressed bridge of the nose, wide separation of the orbits, and irregular dentition with malocclusion. There was also bilateral genu valgum deformity. The eyes were normal. Routine laboratory tests were inconclusive. No blood studies were performed.

Radiological examination of the skull and long bones (Fig. 3) demonstrated changes similar to those seen in his elder brother.

\section{Comment}

Known as "familial metaphyseal dysplasia" to earlier workers, this condition was subsequently redesignated "craniometaphyseal dysplasia" when the severe skull changes accompanying the malformation came to be recognized.

As in most bony dysplasias, the aetiology of craniometaphyseal dysplasia remains undetermined. Developmentally, the metaphyseal cortex is composed of secondary spongiosa and in the modelling process the perichondrial ring of osteoclasts whittles away metaphyseal bone to produce funnelization (Leblond, Wilkinson, Bélanger, and Robichon, 1950). Any failure of osteoclastic activity will result in a splaying of the metaphysis.

Ocular manifestations in this disease occur as a sequel to the sclerotic process in the base of the skull. Narrowing of the optic canals leads to optic atrophy, visual loss, and nystagmus as seen in Case I and also in a case reported by Jackson, Albright, Drewry, Hanelin, and Rubin (1954). The corneal opacities in Case I seem to be coincidental. Preservation of sight in Case 2, even after severe sclerotic changes in the cranium, indicates that the optic canals were spared. It is generally agreed that radiology is the best means of diagnosing this dysplasia. The entire skeleton should be surveyed rather than only the long bones. Cases of leontiasis ossea should be carefully screened to exclude other bone dysplasias because it is not unusual for cases of craniometaphyseal dysplasia ultimately to resemble leontiasis ossea. 


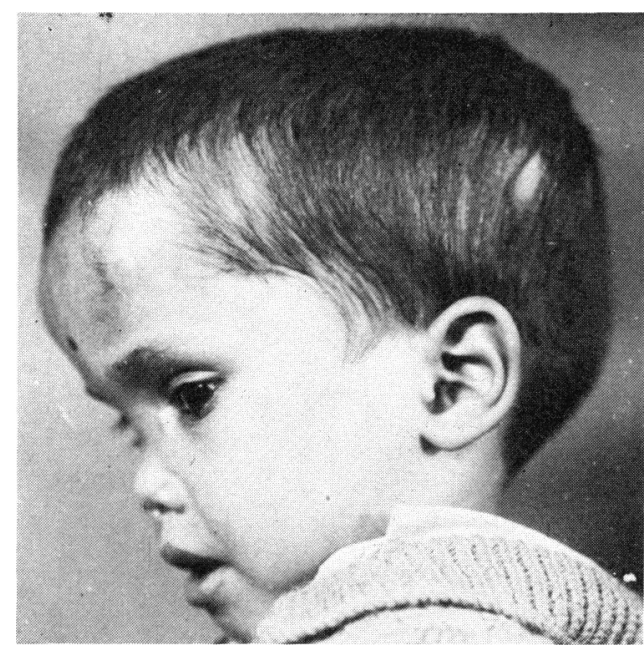

FI 2 Case 2. Marked frontal bossing, a large head, and depressed bridge of nose

FI G. $3 X$ rays of legs of Case 2, showing sclerosis of the shafts and splaying of the metaphyses of the long bones

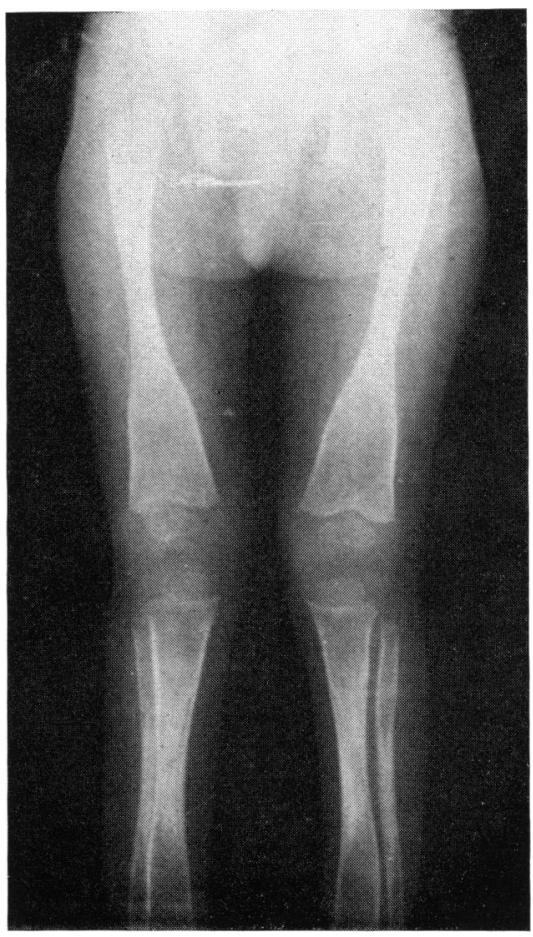

\section{Summary}

Two cases of craniometaphyseal dysplasia occurring in siblings are described. The desirability of a complete skeletal survey with prolonged follow-up is emphasized.

\section{References}

ELlis, R. W. B. (i934) Proc. roy. Soc. Med., 27, 1563

FIELD, C. E. (1939) Ibid., 32, 320

GEMMELL, J. H. L. (1935) Radiology, 25, 723

hallidaY, J. (1949) Brit. J. Surg., 37, 52

JACKSON, W. P. U., Albright, F., DReWRy, G., hanelin, J., and RUbin, M.I. (1954) Arch. intern. Med., 94, 87 I

LEblond, c. P., Wilkinson, G. W., BÉlanger, l. f., and robichon, J. (1950) Amer. F. Anat., 86, 289 LehmanN, E. C. H. (1957) $\quad$ f. Bone Ft Surg., 39B, $3^{1} 3$

MillaRd, D. R., JR., MAisels, D. O., Batstone, J. H. F., and yates, B. w. (1967) Amer. F. Surg., I13, 615

MORI, P. A., and holT, J. F. (1956) Radiology, 66, 335

PyLE, E. (1931) F. Bone Ft Surg., 13, 874

RUBin, P. (1964) "Dynamic Classification of Bone Dysplasias", p. 28o. Year Book Medical Publishers, Chicago 